\title{
Development and validation of The Inventory of Psychotic-Like Anomalous World Experiences (IPAWE): preliminary results in the Portuguese population
}

João Rema, Tânia Cavaco, Joana Pereira, Mariana Melo, Teresa Filipe, Diana Pereira, Maria Moreno, João Eira, Guilherme Queiroz, Luís Madeira

\section{Background \& Aims}

Disorders of the lived world, along with anomalous self-experiences, have long been recognized as key features of schizophrenia spectrum disorders with both diagnostic and prognostic value, while supporting the latest neurobiological correlates. Tools like the Examination of Anomalous Self Experience (EASE) and Examination of Anomalous World Experiences (EAWE) are employed to explore anomalous experiences, but lack clinical and empirical research framework applicability due to their time requirements. This poster shares the development of the Inventory of Psychotic-Like Anomalous World Experiences (IPAWE) - a self-reported version EAWE interview - and its preliminary results.

\section{Building the scale}

A self-reported version was created based on the already validated Portuguese version of the EAWE. Descriptive information was added to each question of the EAWE based on the reports from preceding interviewees. The version obtained was back translated and revised by the original authors.

\section{EAWE - Self Report Version}

The original authors suggested EAWE - Self Report as the new name for the tool (EAWE-SR). It is a 70-item (with 205 subtypes), self-report scale developed for the assessment of anomalous subjective experiences, with an estimated time of 30 minutes to completion and 3-4 minutes to score. It is divided into six subscales: (1) the Space-and-objects domain; (2) the Time-and-events domain; (3) the Other-persons domain; (4) the Language domain; (5) the Atmosphere domain and (6) the Existential-orientation domain. Scoring is made both dichotomously by considering presence or absence and through a 4 item Likert-scale concerning the experience .

\section{Current Work \& Examples}

The interviews (50 patients) necessary for the validation are currently underway. As examples of the finished scale, we provide 2 itens with the main features in italic and the corresponding descriptive citations:

\begin{tabular}{|c|c|c|c|c|}
\hline & $\begin{array}{l}\text { I have never } \\
\text { experienced } \\
\text { this }\end{array}$ & $\begin{array}{l}\text { I have only } \\
\text { experienced this } \\
\text { occasionally }\end{array}$ & $\begin{array}{c}\text { I have } \\
\text { experienced } \\
\text { this frequently }\end{array}$ & $\begin{array}{l}\text { I experience } \\
\text { this everyday } \\
\text { or constantly }\end{array}$ \\
\hline $\begin{array}{l}\text { 2.4.3 I have felt as though every possible outcome of a particula } \\
\text { event was equally likely, as if anything at all could happen. } \\
\text { E.g. There's this weird feeling that anything could be } \\
\text { around the corner - monsters, the end of the world - } \\
\text { and it seems like any of it could in fact happen." }\end{array}$ & & & & \\
\hline $\begin{array}{l}\text { 6.1.2 I tend to act contrary to social norms, perhaps } \\
\text { feeling disgust or skepticism toward these norms. } \\
\text { E.g: "My aversion to common sense is stronger than my } \\
\text { instinct to survive." }\end{array}$ & & & & \\
\hline
\end{tabular}

\section{Final Remarks}

Recent empirical knowledge on the matter of self and lived world anomalous experiences grows as new tools are established to study the phenomenological frameset of experience in psychiatric patients. More clinical suitable scales, such as self-reported versions, allow for a broaden exploration of the living world subjective disturbances in mental illness patients and grant a deeper understanding on the dynamics of the underlying psychopathology.

1. Sass, L., Pienkos, E., Skodlar, B., Stanghellini, G., Fuchs, T., Parnas, J., \& Jones, N. (2017). EAWE: Examination of Anomalous World Experience. Psychopathology. 